\title{
Enhanced Propylene Oxide Selectivity for Gas Phase Direct Propylene Epoxidation by Lattice Expansion of Silver Atoms on Nickel Nanoparticles
}

Bin $\mathrm{Yu}^{\mathrm{a}} \dagger$, Tuğçe Ayvalı ${ }^{\mathrm{a}} \dagger$, Elizabeth Raine ${ }^{\mathrm{a}}$, Tong $\mathrm{Li}^{\mathrm{b}}$, Molly Meng-Jung Li ${ }^{\mathrm{a}}$, Jianwei Zheng ${ }^{\mathrm{a}}$, Simson $\mathrm{Wu}^{\mathrm{a}}$, Abdulaziz A. Bagabas ${ }^{\mathrm{c}}$ and Shik Chi Edman Tsang*

a. Wolfson Catalysis Centre, Department of Chemistry, University of Oxford, Oxford, OX1 3QR, UK; Email: edman.tsang@chem.ox.ac.uk

b. Institute for Materials \& ZGH, Ruhr-Universität Bochum, Universitätsstr. 150, 44801 Bochum, Germany

c. National Petrochemical Technology Center (NPTC), Materials Science Research Institute (MSRI), King Abdulaziz City for Science and Technology (KACST), P. O. Box 6086, Riyadh 11442, Kingdom of Saudi Arabia

† These authors contributed equally.

\section{Abstract}

A series of surfactant-free nickel-core and silver-shell ( $\mathrm{Ni@Ag)} \mathrm{nanoparticles} \mathrm{encapsulated} \mathrm{within} \mathrm{the}$ mesopores of SBA-15 were synthesized and tested as catalysts for direct propylene oxidation by molecular oxygen. The influences of temperature, Gas Hour Space Velocity (GHSV) and Ni/Ag ratio on catalytic activity were systematically investigated. Among the prepared samples, $\mathrm{Ni}_{1} \mathrm{Ag}_{0.4} / \mathrm{SBA}-15$ exhibited the best catalytic performance with selectivity of $70.7 \%$ and PO production rate of 4.4 $\mathrm{nmol} / \mathrm{g} / \mathrm{s}$ under 1 bar at $220^{\circ} \mathrm{C}$ with GHSV of $192 \mathrm{~h}^{-1}$. High selectivity was attributed to longer $\mathrm{Ag}-\mathrm{Ag}$ interatomic distance obtained by careful engineering the thickness of $\mathrm{Ag}$ shell over preformed $\mathrm{Ni}$ nanoparticles. In addition, all prepared new Ni@Ag core-shell catalysts presented excellent stability, which could maintain the conversion and selectivity for at least 10 hours. These results suggest that new designs based on Ag surface atoms tailoring might pave the way to highly efficient and robust Ag catalysts for direct propylene oxidation using molecular oxygen as sole oxidant.

\section{Keywords}

Epoxidation, Propylene, Silver-Nickel, Core-Shell Nanoparticle, Lattice expansion 


\section{Introduction}

The oxidation of alkenes constitutes a very important class of reactions in the chemical industry because the oxidized products are used to manufacture a wide range of commodities. Among the oxidized products, propylene oxide (PO) is an important bulk chemical used in the synthesis of polyurethane, organic intermediates and solvents such as propylene glycols, which are then used in the manufacturing of rigid foams, flexible foams, coatings, adhesives and polyester resins $[1,2]$. In the industrial scale synthesis of $\mathrm{PO}$, propylene is used as a raw material. Approximately $7 \%$ of the world consumption of propylene is for PO production, representing the third most significant product generated from this precursor, coming after polypropylene (62\%) and acrylonitrile (8\%) [3]. Currently, PO is produced via multiple reaction steps in the liquid phase, using hazardous chlorine (chlorohydrin process) or expensive hydroperoxides (hydroperoxide process) as oxidants [1,2]. Beside using toxic, corrosive or explosive reagents, those processes suffer from significant amount of waste by-products which bring separation/purification and disposal problems. Thus, there is a strong demand for new developments of a simple and green process to produce PO. As molecular oxygen is the cheapest and most abundant oxidant, the epoxidation of propylene by molecular oxygen is a topic of great interest. Silver based catalysts have been wildly investigated and have been successfully used for direct epoxidation of ethylene by molecular oxygen on an industrial scale for many years [4,5]. However, the direct catalytic epoxidation of propylene over silver catalysts always gives a very poor propylene oxide selectivity at extremely low conversions as compared to ethylene [6-9] due to easy stripping of allylic hydrogen of propylene and $\mathrm{y}-\mathrm{H}$ atoms of the reaction intermediates by oxygen adatoms which readily lead to the total oxidation to combustion products $\left(\mathrm{CO}_{2}\right.$ and $\left.\mathrm{H}_{2} \mathrm{O}\right)[10,11]$. In the last few decades, numerous attempts have been made to improve the catalytic activity of $\mathrm{Ag}$ catalysts by investigating the effects of promoters [8,12], size of $\mathrm{Ag}$ nanoparticles $[13,14]$, type of supports $[15,16]$ or preparation methods $[15,17]$. However, the progress on improving activity towards $\mathrm{PO}$ is still not significant to attract industrial interests. A detailed understanding on the relationships between activity and selectivity to the variations in the $\mathrm{Ag}$ catalyst structure is therefore further required.

It is well known that size effect of metal nanoparticles can significantly influence the catalyst activity. In general, there is a motivation to develop small size nanoparticles $(<10 \mathrm{~nm})$ due to higher surface area. However, small Ag nanoparticles were found to be detrimental for high PO selectivity in direct propylene epoxidation [14]. This is mainly because specific facets of $\mathrm{Ag}$ nanostructures are found to be selective to propylene transformation to PO under oxygen $[11,14]$ and it is difficult to control the exposure of these specific facets in small size dimension. On the other hand, our group have previously demonstrated the preparation of surfactant-free small silver-shell and nickel-core 
nanoparticles (core@shell : Ni@Ag) where it may be possible to engineer its thickness [18], thus affecting the reactivity of silver shell for this reaction using mesoporous SBA-15 as template.

Herein, we report a systematic work performed to develop a series of surfactant-free Ni@Ag nanoparticles entrapped within the mesopores of SBA-15 (Ni@Ag/SBA-15) with architecting the thickness of $\mathrm{Ag}$ shell atoms in order to improve activity of $\mathrm{Ag}$ atoms towards $\mathrm{PO}$ during direct propylene epoxidation in small size scale for high atom efficiency. A detailed catalytic testing of the as-prepared Ni@Ag/SBA-15 catalysts under various reaction conditions, including temperature, gas hourly space velocity (GSHV) and $\mathrm{Ni} / \mathrm{Ag}$ molar ratio were conducted to achieve the optimized catalytic activity and selectivity. The materials' structures and properties were characterised using advanced techniques including Synchrotron X-Ray Powder Diffraction (SXRD), Transmission Electron Microscopy (TEM), Atom Probe Tomography (APT), High Sensitivity Low-Energy Ion Scattering (HSLEIS), Extended X-ray Absorption Fine Structure (EXAFS) and X-ray Photoelectron Spectroscopy (XPS) to gain a deeper understanding of structure-activity relationships of these $\mathrm{Ag}$ shell atoms via surface tailoring the average interatomic Ag distances on Ni@Ag/SBA15 catalysts.

\section{Experimental}

A detailed discussion of experimental methods can be found in Supporting Information (SI). A brief summary of catalysts' syntheses and catalytic test conditions is given here.

\subsection{Synthesis}

The ordered silica-block copolymer mesoporous SBA-15 were synthesized by a modified method according to Zhao \& Stucky's work [19]. The core@shell bimetallic Ni@Ag/SBA-15 catalysts with a silver loading of $5 \mathrm{wt} \%$ were prepared using a co-impregnation method according to our previous report but this time more fine control in Ag shell thickness was conducted [18]. The bimetallic catalysts were denoted as $\mathrm{Ni}_{x} \mathrm{Ag}_{\mathrm{y}} / \mathrm{SBA}-15$, where $\mathrm{x}$ and $\mathrm{y}$ represent the nominal atomic relative ratios of $\mathrm{Ag}$ and $\mathrm{Ni}$ to each other.

\subsection{Catalytic Test}

The reactions were performed in a vertical tubular fixed bed reactor. The desired amount of catalyst was packed between quartz wool in the middle part of the reactor tube. The reactant gas mixture of $5 \% \mathrm{C}_{3} \mathrm{H}_{6}$ in helium and $5 \% \mathrm{O}_{2}$ in helium with a mix ratio of $2: 1\left(3.33 \% \mathrm{C}_{3} \mathrm{H}_{6}: 1.67 \% \mathrm{O}_{2}: 95 \%\right.$ $\mathrm{He}$ ) at a total flow rate of $20 \mathrm{~mL} / \mathrm{min}$ was delivered from the top of the reactor. The reactants and products were analysed online by Schimadzu GC-2014 gas chromatograph equipped with a methanizer and a flame ionization detector (FID). 


\section{Results and Discussion}

\subsection{Catalytic Performance}

\subsubsection{Temperature Effect}

First $\mathrm{Ni}_{0.4} \mathrm{Ag}_{1} / \mathrm{SBA}-15$ catalyst having $\mathrm{Ni} / \mathrm{Ag}$ molar ratio of 0.4 was selected and synthesized as a catalyst for direct propylene epoxidation with molecular oxygen at a variety of reaction temperatures in order to study the temperature effect. The catalytic performance of $\mathrm{Ni}_{0.4} \mathrm{Ag}_{1} / \mathrm{SBA}-15$ catalyst, in terms of PO selectivity and rate of PO productivity, with the loading of 50mg is shown in Figure 1. It can be seen that propylene oxide and $\mathrm{CO}_{2}$ are the only products. Started from $220^{\circ} \mathrm{C}$, the rate of propylene oxidation increases sharply with temperature from $2.0 \mathrm{nmol} / \mathrm{g} / \mathrm{s}$ to $39.3 \mathrm{nmol} / \mathrm{g} / \mathrm{s}$ at $300{ }^{\circ} \mathrm{C}$. The formation of propylene oxide is observed at $220{ }^{\circ} \mathrm{C}$ with a remarkable $70.6 \%$ selectivity, which is considerably higher than that of most Ag based catalysts reported in the literature, particularly from $\mathrm{Ag}-\mathrm{Ni} / \mathrm{Al}_{2} \mathrm{O}_{3}$ catalyst $[1,20]$. It should be noted that direct activation of dioxygen and propylene to propylene oxide over this core-shell catalyst is clearly evident without a strong metal-support interaction (SMSI). The selectivity of propylene oxide progressively decreases as the temperature increases which eventually drops to only $11.1 \%$ at $300{ }^{\circ} \mathrm{C}$. In contrast, the selectivity of combustion product, $\mathrm{CO}_{2}$, increases sharply from $29.4 \%$ at $220{ }^{\circ} \mathrm{C}$ to $88.9 \%$ at $300{ }^{\circ} \mathrm{C}$. The observation for the formation of $\mathrm{CO}_{2}$ at the expense of the partial oxidised product, propylene oxide, at elevated temperature is because their formation routes are temperature dependent and competitive [21]. Although at high temperature, the kinetics favours the increase in rate of propylene oxidation, the combustion is more favourable over the partial oxidation of propylene to $\mathrm{PO}$, leading to $\mathrm{CO}_{2}$ as the major product.
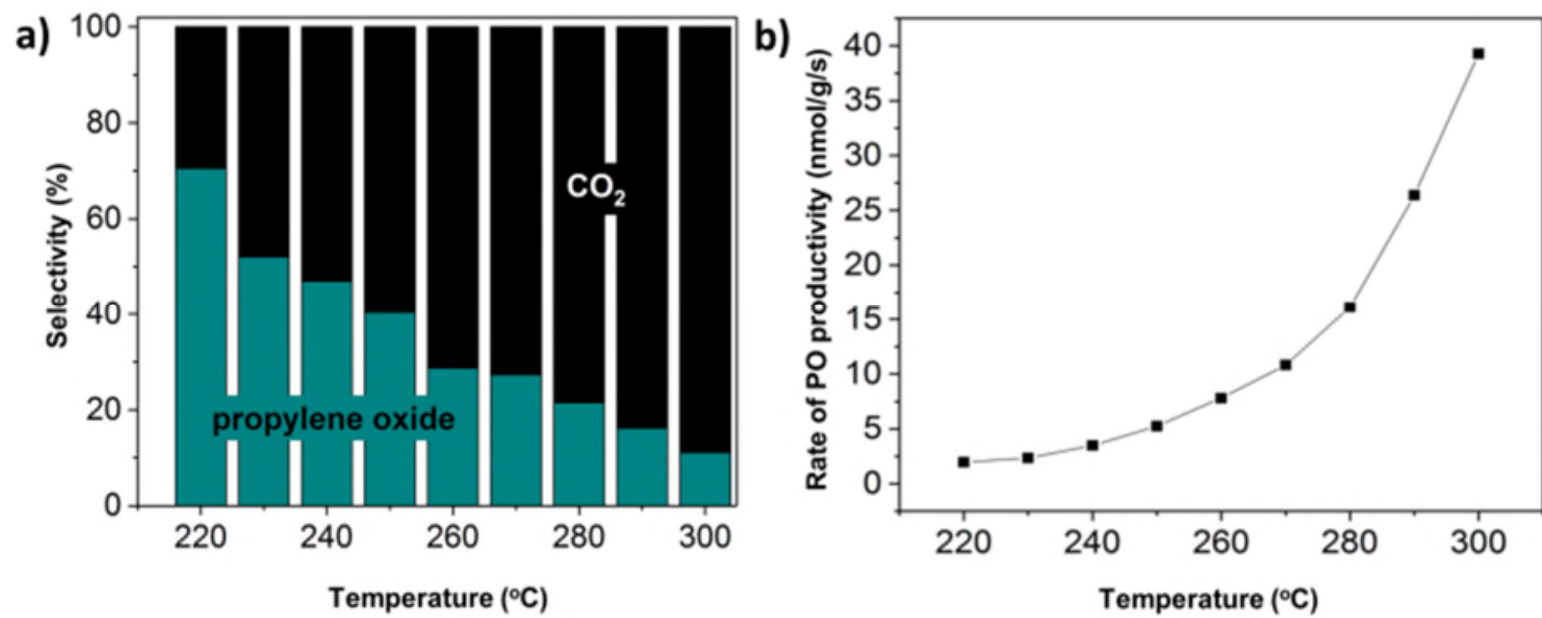

Figure 1 a) Selectivity profile and b) Rate of propylene oxidation of $\mathrm{Ni}_{0.4} \mathrm{Ag}_{1} / \mathrm{SBA}-15$ as a function of temperature. 


\subsubsection{Effect of GHSV}

Although the $\mathrm{Ni}_{0.4} \mathrm{Ag}_{1} / \mathrm{SBA}-15$ catalyst exhibited a promising selectivity towards propylene oxide at $220^{\circ} \mathrm{C}$, the rate of propylene oxidation remained limited. In order to improve the rate of propylene oxidation, the $\mathrm{Ni}_{0.4} \mathrm{Ag}_{1} / \mathrm{SBA}-15$ catalyst was tested under isothermal conditions at $220{ }^{\circ} \mathrm{C}$ with 5 different loadings, namely: $50 \mathrm{mg}, 100 \mathrm{mg}, 200 \mathrm{mg} 300 \mathrm{mg}$ and $500 \mathrm{mg}$ while keeping gas flow constant $\left(20 \mathrm{~mL} \cdot \mathrm{min}^{-1}\right)$. The reaction results are shown in Figure 2 as a function of gas hourly space velocity (GHSV). The rate of PO production shows nearly a constant value for all 5 different GHSVs. However, the total propylene conversion is dramatically changed with different GHSV. When GHSV is $1920 \mathrm{~h}^{-1}$, the total propylene conversion is only $0.03 \%$ at $220^{\circ} \mathrm{C}$. The conversion progressively increases from GHSV of 1920 to $192 \mathrm{~h}^{-1}$ summiting to $0.62 \%$ with GHSV of $192 \mathrm{~h}^{-1}$, almost 20 times more than that of $1920 \mathrm{~h}^{-1}$. The selectivity of propylene oxide shown in Figure $2 \mathrm{~b}$, on the other hand, gives a strikingly different trend. The selectivity of propylene oxide sharply drops from $70.6 \%$ to $56.7 \%$, when the GHSV is decreased from 1920 to $960 \mathrm{~h}^{-1}$. As GHSV decreases to $320 \mathrm{~h}^{-1}$, only a slight fall in propylene oxide selectivity (52.1\%) is observed. The further decline of GHSV to $192 \mathrm{~h}^{-1}$ leads to additional drop in PO selectivity to $41.4 \%$. In general, higher catalyst loading (lower GHSV) leads to longer reaction residence time or contact time for the partial oxidised products to be in touch with oxygen over the same catalyst. Thus, the partially oxidized products are further oxidized to the combustion product as the secondary product resulting in a decrease in selectivity. However, the relationship between catalyst amount with residence time or contact time may not be linear due to the contribution of direct combustion from unselective sites, flow characteristics and packing of catalyst bed, etc [22-24].
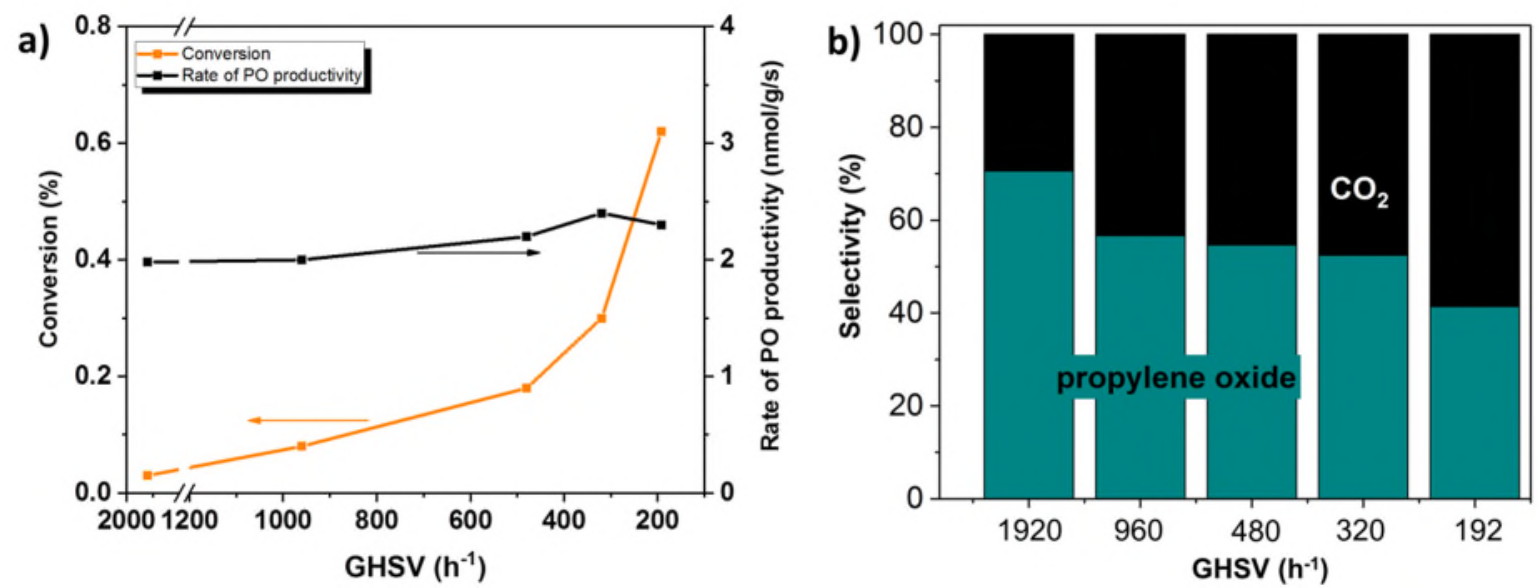

Figure 2 Effect of GHSV on a) Rate of propylene oxidation and Conversion, b) Selectivity profile of $\mathrm{Ni}_{0.4} \mathrm{Ag}_{1} / \mathrm{SBA}-15$. Reaction conditions: 1 bar, $20 \mathrm{~mL} / \mathrm{min}$ total gas flow $\left(3.33 \% \mathrm{C}_{3} \mathrm{H}_{6}: 1.67 \% \mathrm{O}_{2}: 95 \% \mathrm{He}\right), 220{ }^{\circ} \mathrm{C}$, catalyst amounts: $50,100,200,300,500 \mathrm{mg}$. 


\subsubsection{Effect of Ni/Ag Molar Ratio}

In order to examine the effect of surface structure modification of Ag to PO production rate and find the optimum conditions for highest PO production, we also studied the effect of $\mathrm{Ni} / \mathrm{Ag}$ ratio within the catalysts. A series of bimetallic Ni@Ag core-shell catalysts with a variation of $\mathrm{Ni}$ to $\mathrm{Ag}$ atomic ratios was synthesized and tested in direct propylene epoxidation at $220{ }^{\circ} \mathrm{C}$ under $1 \mathrm{bar}$ pressure with total gas flow of $20 \mathrm{~mL} / \mathrm{min}\left(3.33 \% \mathrm{C}_{3} \mathrm{H}_{6}: 1.67 \% \mathrm{O}_{2}: 95 \% \mathrm{He}\right)$ and $500 \mathrm{mg}$ catalyst loading. Ag/SBA-15 and Ni/SBA-15 catalysts were also synthesized and tested for comparison.

Table 1 shows the catalytic performances of Ni@Ag/SBA-15 catalysts for the direct propylene epoxidation at $220^{\circ} \mathrm{C}$. It can be seen that $\mathrm{Ni} / \mathrm{SBA}-15$ catalyst displays no activity towards the formation of propylene oxide, presumably the Ni particle might have been fully oxidised to NiO in air $[25,26]$. Over all silver containing $\mathrm{Ni@Ag/SBA-15}$ samples, the propylene oxide and $\mathrm{CO}_{2}$ are the two major products at $220^{\circ} \mathrm{C}$. For the $\mathrm{Ag} / \mathrm{SBA}-15$, the selectivity of propylene oxide is kept at only $9.9 \%$ with the rate of production of $1.78 \mathrm{nmol} / \mathrm{g} / \mathrm{s}$ while $\mathrm{CO}_{2}$ selectivity of $87.3 \%$ is recorded. At higher ratios of $\mathrm{Ni}$ to $\mathrm{Ag}$, the selectivity of propylene oxide is dramatically enhanced, reaching a maximum of $70.7 \%$ which is much higher than most of supported silver catalysts reported in the literature as mentioned earlier $[9,13,27,28]$. Comparing to the monometallic $\mathrm{Ag} / \mathrm{SBA}-15$, the bimetallic $\mathrm{Ni@Ag/SBA-15}$ catalysts are much more selective to epoxidation which becomes the dominant product when $\mathrm{Ni}$ to $\mathrm{Ag}$ ratio is higher than 2.5 . It is interesting to note that the selectivity of propylene oxide over the catalysts follows the increasing order: Ag/SBA-15< $\mathrm{Ni}_{0.2} \mathrm{Ag}_{1} / \mathrm{SBA}-15<$ $\mathrm{Ni}_{0.4} \mathrm{Ag}_{1} / \mathrm{SBA}-15<\mathrm{Ni}_{1} \mathrm{Ag}_{0.4} / \mathrm{SBA}-15$ (decreasing $\mathrm{Ag}: \mathrm{Ni}$ ratio). The same order for the rate of propylene oxide formation is also obtained, in which $\mathrm{Ag} / \mathrm{SBA} 15$ displays the lowest rate while $\mathrm{Ni}_{1} \mathrm{Ag}_{0.4} / \mathrm{SBA}-15$ shows the highest rate (Table 1). This means that the thinner Ag shells on Ni nanoparticle with lower Ag:Ni ratios synthesised in a size-fixed $4.6 \pm 0.5 \mathrm{~nm}$ channel [29] can give higher propylene oxide selectivity and activity. The volcano relationship where mono-metallic $\mathrm{Ni}$ and $\mathrm{Ag}$ show poor $\mathrm{PO}$ selectivity while the optimal selectivity peaks with $\mathrm{Ni}_{1} \mathrm{Ag}_{0.4} / \mathrm{SBA}-15$ is evidenced. These results are significant from two important perspectives. First, it demonstrates that the $\mathrm{Ni}_{1} \mathrm{Ag}_{0.4} / \mathrm{SBA}-15$ catalyst processes a remarkable activity and selectivity for the direct oxidation of propylene to propylene oxide, and to our knowledge, developing such core-shell catalysts for this reaction have not yet reported. Most importantly, it is shown that, by changing the Ni/Ag ratios, the catalytic routes on $\mathrm{Ag}$ atoms as catalysts can be modified from favoured combustion to epoxidation favoured pathways. 
Table 1 Catalytic performances of Ag/SBA-15, Ni/SBA-15 and Ni@Ag/SBA-15 (500mg) for direct propylene epoxidation at $220^{\circ} \mathrm{C}$ under 1 bar with $20 \mathrm{~mL} / \mathrm{min}\left(3.33 \% \mathrm{C}_{3} \mathrm{H}_{6}: 1.67 \% \mathrm{O}_{2}: 95 \% \mathrm{He}\right)$ total gas flow.

\begin{tabular}{cccc}
\hline Catalyst & $\begin{array}{c}\text { Rate of PO } \\
\text { Productivity (nmol/g/s) }\end{array}$ & $\begin{array}{c}\text { Selectivity (\%) } \\
\text { Propylene oxide }\end{array}$ & $\mathbf{C O}_{\mathbf{2}}$ \\
\hline $\mathrm{Ag} / \mathrm{SBA}-15$ & 1.78 & 9.9 & 87.3 \\
$\mathrm{Ni}_{0.2} \mathrm{Ag}_{1} / \mathrm{SBA}-15$ & 2.01 & 28.5 & 71.5 \\
$\mathrm{Ni}_{0.4} \mathrm{Ag}_{1} / \mathrm{SBA}-15$ & 2.30 & 41.4 & 58.6 \\
$\mathrm{Ni}_{1} \mathrm{Ag}_{0.4} / \mathrm{SBA}-15$ & 4.40 & 70.7 & 29.3 \\
$\mathrm{Ni}_{1} \mathrm{Ag}_{0.2} / \mathrm{SBA}-15$ & 3.85 & 60.2 & 39.8 \\
$\mathrm{Ni} / \mathrm{SBA}-15$ & 0 & 0 & 0 \\
\hline
\end{tabular}

\subsubsection{Catalyst Stability}

Catalysts stability tests were conducted at $220^{\circ} \mathrm{C}$ for 10 hours with $500 \mathrm{mg}$ catalyst loading to evaluate the stability of $\mathrm{Ag}$ structure with time stream under reaction conditions. The reaction results over bimetallic Ni@Ag/SBA-15, and monometallic Ag/SBA-15 are shown in Figure 3. According to the results, all the catalysts maintain their stable catalytic performances over the 10 hours reaction time. Conventionally, supported Ag metal can suffer from a rapid time-deactivation, due to facile aggregation of thermal labile $\mathrm{Ag}$ atoms at elevated temperature [13]. However, in our case, using SBA-15 catalysts, Ag atoms as shell on Ni nanoparticle core do not suffer from rapid aggregation, which may be related to the strong interactions between $\mathrm{Ag}$ and $\mathrm{Ni}$ on the SBA-15 template. In addition, the narrow walls with strong wall effect of SBA-15 channels [30] may also reduce the extent of $\mathrm{Ag}$ or $\mathrm{AgNi}$ aggregation [31]. 

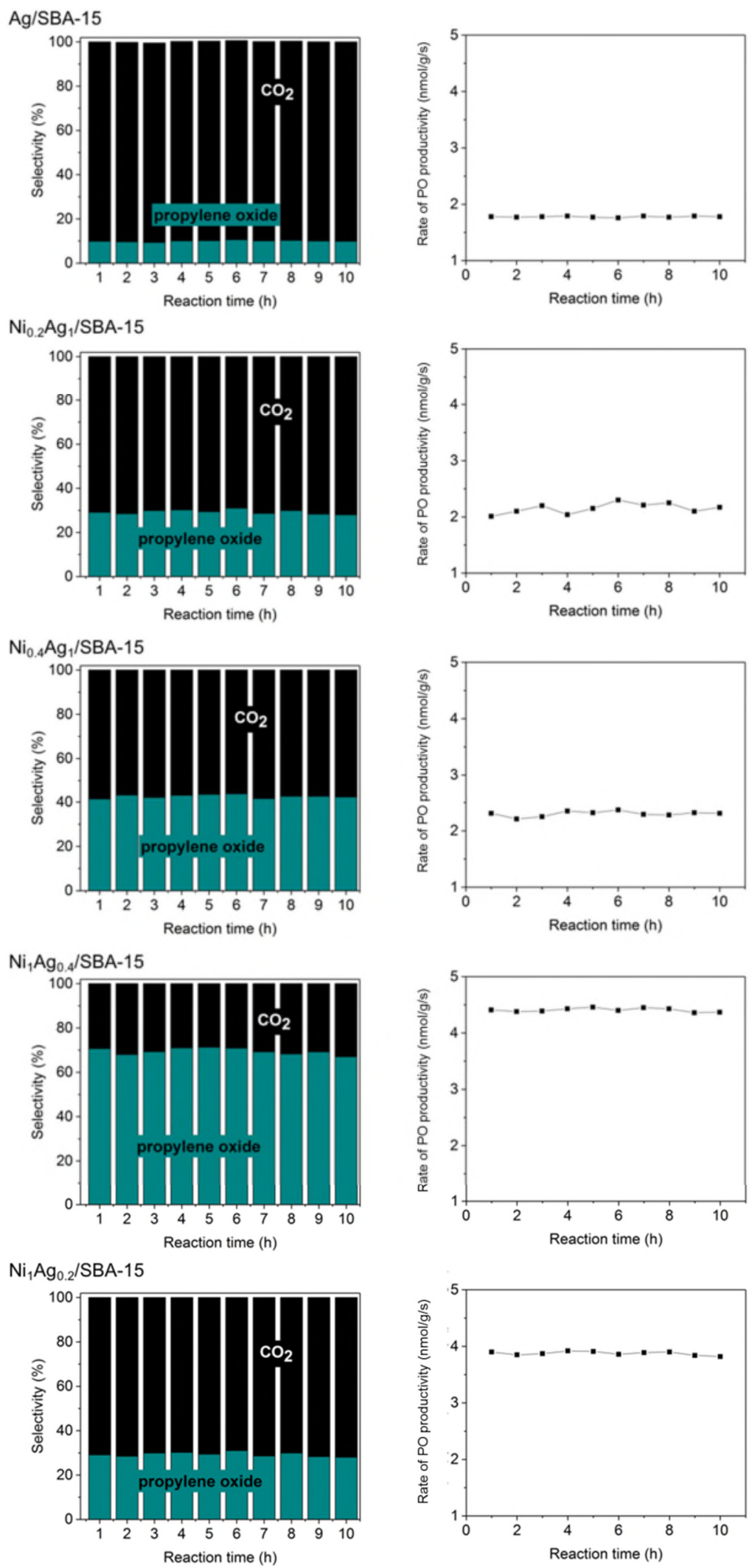

Figure 3 Stability tests results: from top to bottom, left: selectivity of propylene oxide and $\mathrm{CO}_{2}$; right: rate of propylene oxide formation over Ag/SBA-15, Nio.2Ag $1 / \mathrm{SBA}-15, \quad \mathrm{Ni}_{0.4} \mathrm{Ag}_{1} / \mathrm{SBA}-15, \quad \mathrm{Ni}_{1} \mathrm{Ag}_{0.4} / \mathrm{SBA}-15$ and $\mathrm{Ni}_{1} \mathrm{Ag}_{0.2} / \mathrm{SBA}-15$. All catalysts were tested at $220{ }^{\circ} \mathrm{C}, 1$ bar, $20 \mathrm{~mL} / \mathrm{min}\left(3.33 \% \mathrm{C}_{3} \mathrm{H}_{6}: 1.67 \% \mathrm{O}_{2}: 95 \% \mathrm{He}\right)$ total gas flow with $500 \mathrm{mg}$ catalyst loading. 


\subsection{Characterization}

In order to understand structure-activity relationships, all synthesized Ni@Ag/SBA-15 catalysts were characterised using advanced techniques including Synchrotron $\mathrm{X}$-ray powder diffraction (SXRD), High resolution transmission electron microscopy (HRTEM), High sensitivity low-energy ion scattering (HS-LEIS), Atom probe tomography (APT), Extended X-ray absorption fine structure (EXAFS) and X-ray photoelectron spectroscopy (XPS).

\subsubsection{Structural Analysis}

The structural properties of as-prepared catalysts were initially examined by high sensitivity Synchrotron X-ray powder diffraction (SXRD). Figure 4 shows the SXRD patterns of Ag/SBA-15 and $\mathrm{Ni@Ag/SBA-15}$ catalysts collected from I11 beamline using Diamond Light source, UK. Form the SXRD patterns, all the Ag peak positions despite the severe broadening, attributed to small crystalline sizes of $\mathrm{Ag}$ shell atoms, are remained unchanged. The derived lattice parameter of $\mathrm{Ag}$ (Fm-3m) with the samples (marked in red) maintains as $4.08719 \pm 0.00040 \AA$ ( $R_{w p} \%=17.7, G_{\text {of }}=-0.3$ ) as that of pure $\mathrm{Ag}$ phase. For those $\mathrm{Ni}$ containing samples (marked in black), the derived lattice parameter of $\mathrm{Ni}(\mathrm{Fm}-3 \mathrm{~m})$ also maintains as $3.52761 \pm 0.00010 \AA\left(R_{\mathrm{wp}} \%=15.8, G_{\text {of }}=-0.2\right)$ as that of pure $\mathrm{Ni}$ phase. On the other hand, it has been reported that there is a compression in the lattice parameter of $\mathrm{Ag}$ to $4.02 \AA$ if alloy $\mathrm{Ni}_{0.2} \mathrm{Ag}_{1}$ is formed at high temperature [32]. As our core-shell $\mathrm{Ni}_{0.2} \mathrm{Ag}_{1} / \mathrm{SBA}-15$ gives the same lattice parameter of $4.08719 \pm 0.00040 \AA$ as $\mathrm{Ag}$ according to SXRD pattern, we have ruled out the significant alloy formation between the two well segregated coreshell metallic phases.

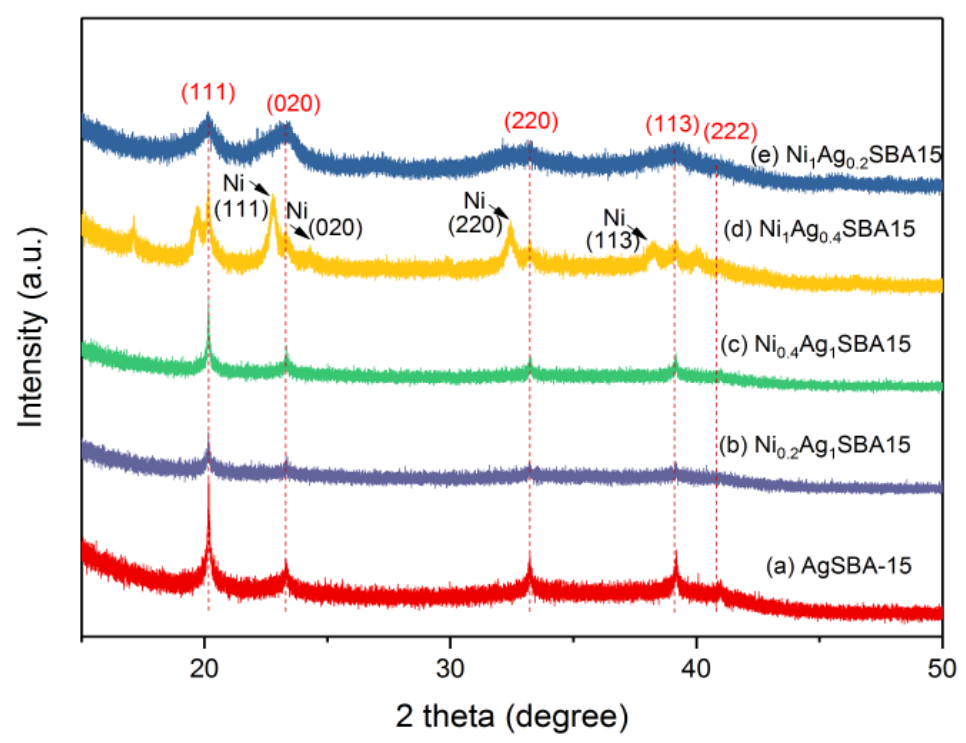

Figure 4 SXRD patterns of (a) Ag/SBA -15, (b) Nio.2Ag $/$ SBA-15, (c) Nio.4Ag $1 / \mathrm{SBA}-15$, (d) $\mathrm{Ni}_{1} \mathrm{Ag}_{0.4} / \mathrm{SBA}-15$ and (e) $\mathrm{Ni}_{1} \mathrm{Ag}_{0.2} / \mathrm{SBA}-15$ 
The visual structural details of SBA-15, Ni@Ag/SBA-15 and isolated Ni@Ag bimetallic nanoparticles were determined using TEM. First, the TEM images of the as-prepared SBA-15 were taken from four randomly chosen areas (Figure S1). All the images depict the well-defined mesoporous silica channels of $4.6 \pm 0.5 \mathrm{~nm}$, as previously been reported $[19,29]$. This confirms the porous ordered structure of SBA-15 with typical cylindrical pore channels with no amorphous region. Thus, SBA-15 offers the high-quality porous template for the preparation of nanoparticles. The TEM images of selected $\mathrm{Ni}_{0.4} \mathrm{Ag}_{1} / \mathrm{SBA}-15$ and $\mathrm{Ni}_{1} \mathrm{Ag}_{0.4} / \mathrm{SBA}-15$ are shown in Figure 5 which confirm the on and filling of cylindrical pore channels with nanoparticles over all these catalysts. The preparation procedure including high temperature calcination and reduction did not seem to induce any structural damage to the mesoporous material. Metal nanoparticles are clearly incorporated into the porous silica matrix, encapsulated by the ordered channel structure and uniformly distributed throughout the entire SBA-15 framework with no significant agglomeration. The average size of $\mathrm{Ni@Ag}$ nanoparticles in $\mathrm{Ni}_{0.4} \mathrm{Ag}_{1} / \mathrm{SBA}-15$ and $\mathrm{Ni}_{1} \mathrm{Ag}_{0.4} / \mathrm{SBA}-15$ samples were found to be similar $(4.5 \pm$ $0.8 \mathrm{~nm}$ and $4.3 \pm 1.1 \mathrm{~nm}$ respectively), which appears to have adopted the SBA-15 channel dimension $(4.6 \pm 0.5 \mathrm{~nm})$ despite the variation in $\mathrm{Ag}$ to Ni ratios.
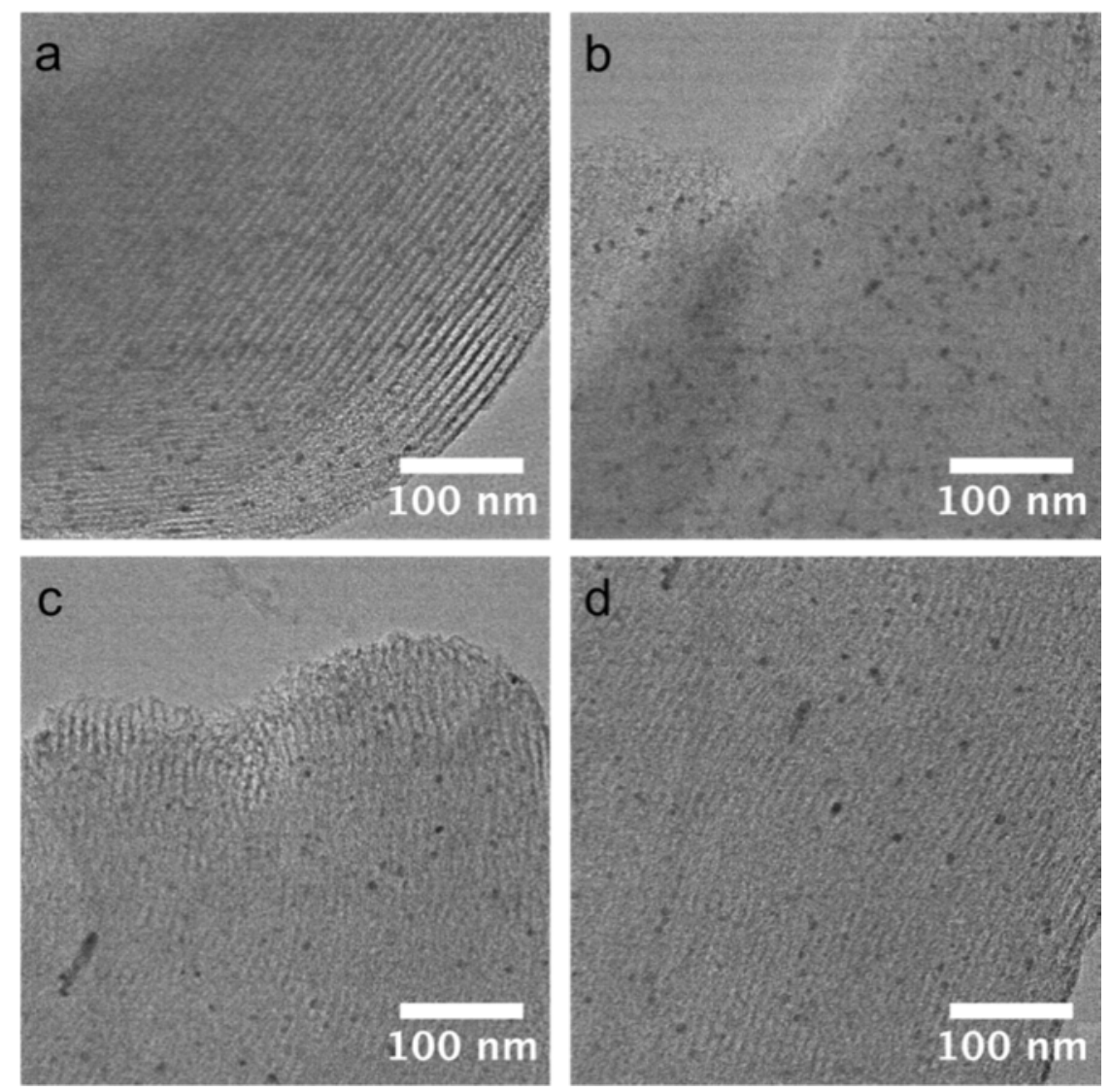

Figure 5 TEM images of SBA-15 showing the $4.6 \pm 0.5 \mathrm{~nm}$ parallel porous channels filled up with $a, b)$ $\mathrm{Ni}_{0.4} \mathrm{Ag}_{1} / \mathrm{SBA}-15$ nanoparticles and $\left.\mathrm{c}, \mathrm{d}\right) \mathrm{Ni}_{1} \mathrm{Ag}_{0.4} / \mathrm{SBA}-15$ nanoparticles of same size where the particles adopt the dimension of the channels. 
In order to determine the chemical order in Ni@Ag nanoparticles, the nanoparticles were isolated by the selective removal of SBA-15 silica using chemical dissolution method and then analysed by HRTEM technique. The HRTEM images of isolated nanoparticles obtained from $\mathrm{Ni}_{0.4} \mathrm{Ag}_{1} / \mathrm{SBA}-15$ and $\mathrm{Ni}_{1} \mathrm{Ag}_{0.4} / \mathrm{SBA}-15$ are shown in Figure S2. There was no change in particle size before and after removal of the SBA-15 template. Two sets of lattice fringes can clearly be observed: the outer but lighter fringe with d-spacing of $0.23 \mathrm{~nm}$ corresponds to $\mathrm{fcc} A g(111)$ [33] and the inner, darker fringe with d-spacing of $0.20 \mathrm{~nm}$ was assigned as $\mathrm{fcc} \mathrm{Ni(111)} \mathrm{[34].} \mathrm{This} \mathrm{may} \mathrm{indicate} \mathrm{the} \mathrm{formation} \mathrm{of}$ $\mathrm{Ni@Ag} \mathrm{core-shell} \mathrm{structure.} \mathrm{It} \mathrm{is} \mathrm{well} \mathrm{accepted} \mathrm{that} \mathrm{Ni}^{2+}$ will prone to reduction to $\mathrm{Ni}$ metal by $\mathrm{H}_{2}$ prior to $\mathrm{Ag}^{+}$. Once the $\mathrm{Ni}^{0}$ phase is formed, it will rapidly catalyse the $\mathrm{Ag}^{+}$reduction to give $\mathrm{Ni}$ core- $\mathrm{Ag}$ shell structure [35-37]. Due to the limited resolution of the TEM images, we could not determine the thickness of Ag shell of the two nanoparticles unambiguously. As a result, further characterisations were conducted.

HS-LEIS is a technique which is able to reflect the composition of a material in the function of depth from the surface. The HS-LEIS depth profiles of $\mathrm{Ni}_{0.4} \mathrm{Ag}_{1}$ and $\mathrm{Ni}_{1} \mathrm{Ag}_{0.4}$ were determined using high energy $\mathrm{Ne}^{+}$beam to strip off surface atoms of known thickness and the results are depicted in Figure 6. The feature peak at region between 2500 to $2750 \mathrm{eV}$ is $\mathrm{Ag}$, and $\mathrm{Ni}$ is between 2250 to 2500 eV. Primarily, $\mathrm{O}$ and Si signals were always detected from the SBA-15 top layers. Upon further stripping, $\mathrm{Ag}$ peaks were first observed followed by the signal coming from inner $\mathrm{Ni}$ atoms, evidencing the $\mathrm{Ag}$ shell and $\mathrm{Ni}$ core nanoparticle configuration in agreement with TEM analyses. Notice that the $\mathrm{Ni}$ peak appears of about ca. $1.14 \mathrm{~nm}$ after the $\mathrm{Ag}$ peak in the case of $\mathrm{Ni}_{0.4} \mathrm{Ag}_{1}$ nanoparticle as shown in Figure 6a. This matches with the model (Figure 6c) built based on theoretical calculations from which $\mathrm{Ag}$ thickness of $1.19 \mathrm{~nm}$ were found on given $\mathrm{Ag} / \mathrm{Ni}$ ratio (1:0.4) by assuming the formation of homogeneous, spherical, core-shell particles of $4.6 \mathrm{~nm}$ diameter, adopting the dimension of the SBA-15 channel. Similarly, the Ni peak appears in between ca. 0.38 to $0.76 \mathrm{~nm}$ after the $\mathrm{Ag}$ peak in case of $\mathrm{Ni}_{1} \mathrm{Ag}_{0.4}$ nanoparticle as shown in Figure 6b. This also matches with the model presented in Figure $6 \mathrm{~d}$ where Ag thickness of $0.63 \mathrm{~nm}$ was calculated theoretically from the given $\mathrm{Ag} / \mathrm{Ni}$ ratio (0.4:1). Their relative peak intensities reflect the chemical compositions of these core-shell nanoparticles. Clearly, Ag atoms are more favourable to segregate on the surface to form $\mathrm{Ag}$ shell and $\mathrm{Ni}$ atoms are embedded in the core without the formation of alloy under our mild synthesis conditions [18,37]. For the Ni@Ag core-shell nanoparticles of different $\mathrm{Ag} / \mathrm{Ni}$ ratios, we demonstrate the tailoring of $\mathrm{Ag}$ shell thickness in this synthesis. 

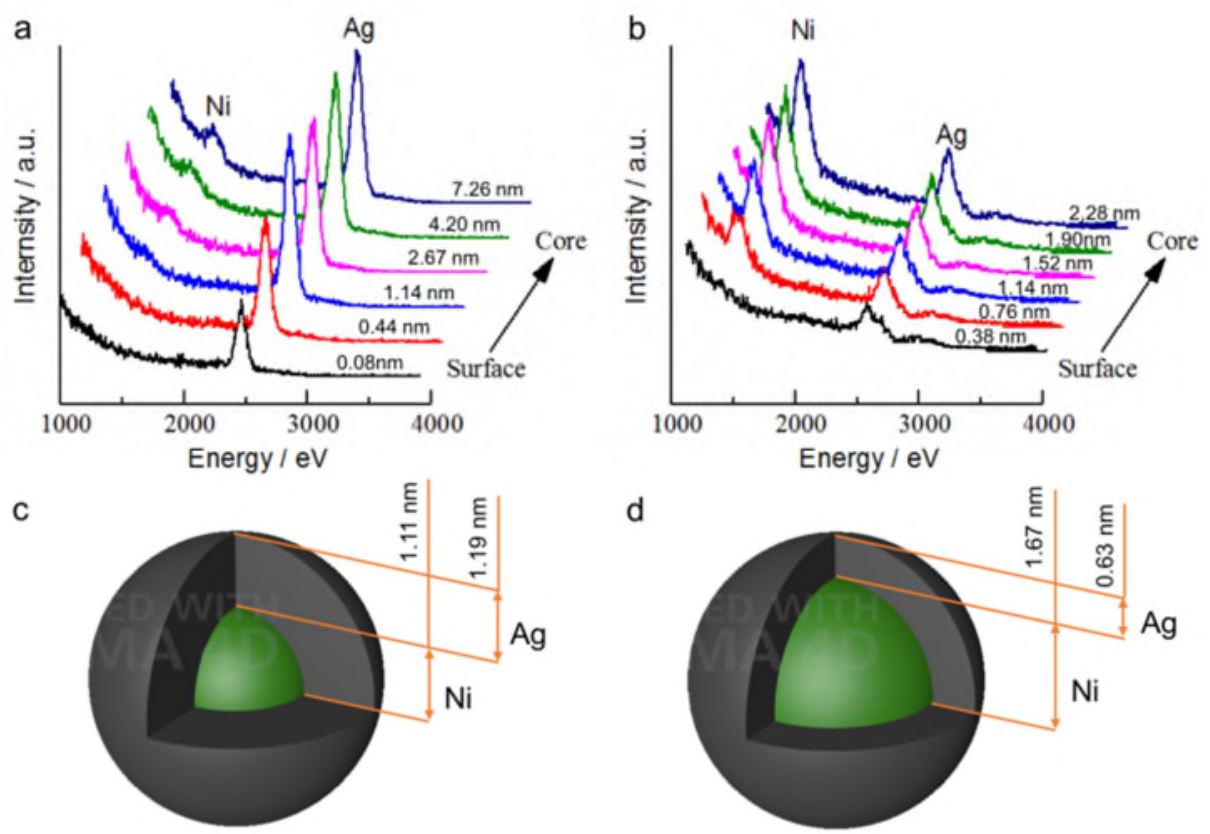

d



$\mathrm{Ni}_{1} \mathrm{Ag}_{0.4}$ nanoparticles

Figure 6 HS-LEIS spectra of a) $\mathrm{Ni}_{0.4 \mathrm{Ag}_{1}}$ and b) $\mathrm{Ni}_{1} \mathrm{Ag}_{0.4}$ with corresponding structural models (c and $\mathrm{d}$ respectively).

APT was also employed to further confirm the core-shell structure, which gave more detailed information about the shell thickness of $\mathrm{Ni@Ag}$ nanoparticles from selected $\mathrm{Ni}_{1} \mathrm{Ag}_{0.4} / \mathrm{SBA}-15$ catalyst which exhibited the best selectivity towards PO. This method has successfully been employed to resolve the core-shell structure of Ag-Pd [38], Pt-Co [39] and CdTe-ZnO nanoparticles or nanocrystals [40] in our previous works. APT data takes the form of a three-dimensional point cloud, in which every point represents a single atom detected and identified by arrays of positional mass spectroscopy in projected screen. Figure 7 clearly shows that $\mathrm{Ni}_{1} \mathrm{Ag}_{0.4} / \mathrm{SBA}-15$ indeed displays a coreshell structure with the shell thickness of 1-3 atomic layers (errors in measurements were encountered due to the preferential evaporation of $\mathrm{Ag}$ atoms and mixed phases) [41]. This corresponds well to the calculated Ag average thickness of $0.63 \mathrm{~nm}$ from HS-LEIS analysis (refer to Figure 6d, vide supra). 


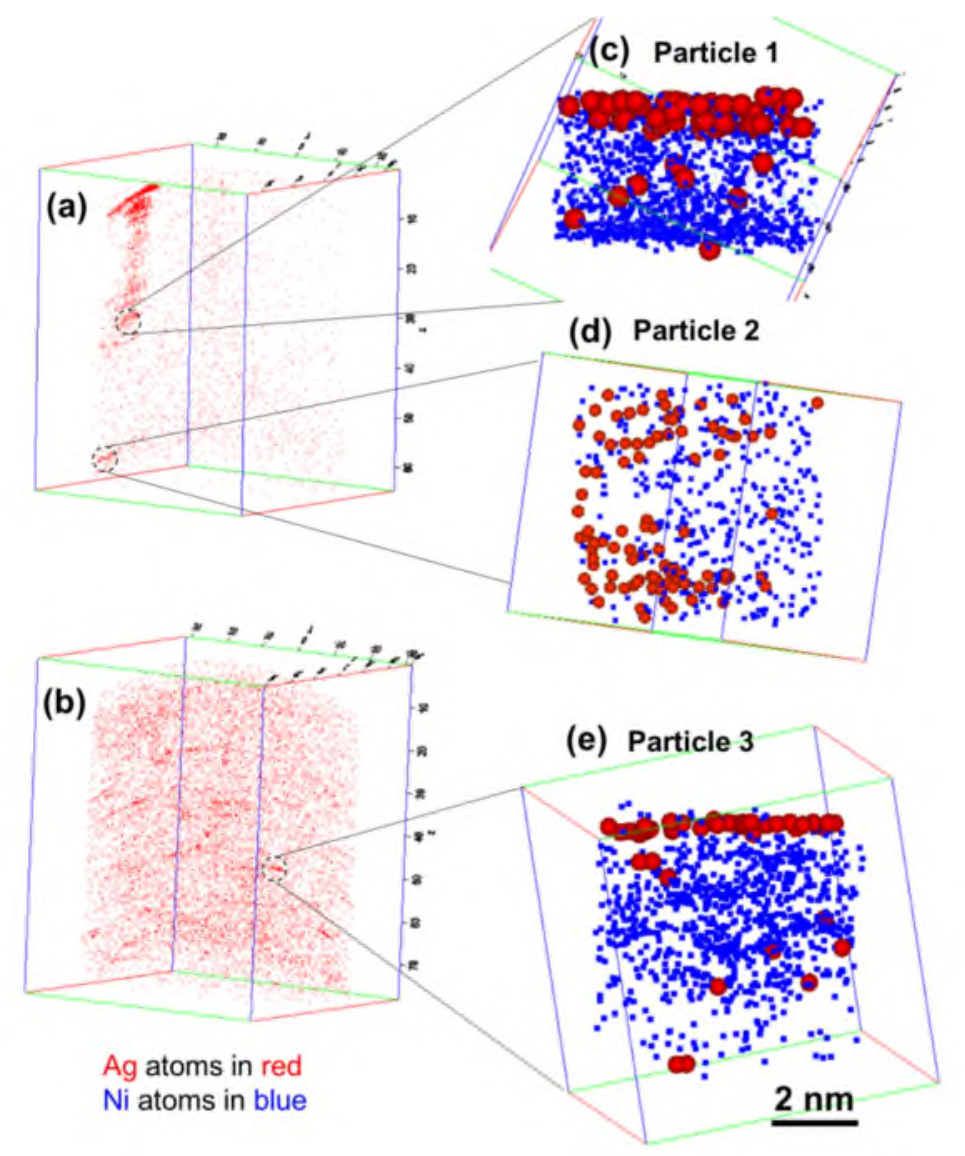

Figure 7 Atom Probe Tomography data taken from $\mathrm{Ni}_{1} \mathrm{Ag}_{0.4} / \mathrm{SBA}-15$. Atom maps on the left measured the $\mathrm{Ag}$ distributions in selective areas of the sample. The enlarged atom maps show both the $\mathrm{Ni}$ and $\mathrm{Ag}$ with condensed atom regions (in silica matrix), which suggest approximately 1-3 atomic shell thickness of $\mathrm{Ag}$ atoms (slightly contaminated with $\mathrm{Ni}$ atoms) on Ni rich particles.

\subsubsection{Surface features of Ag atoms on Ni@Ag bimetallic nanoparticles}

The above characterisations confirm that Ni@Ag nanoparticles are in core@shell bimetallic nature, which are distributed uniformly inside the SBA-15 channels. It also shows that the catalytic activity of core-shell structures is related with the $\mathrm{Ag}: \mathrm{Ni}$ loading ratio. With a high $\mathrm{Ag}$ to $\mathrm{Ni}$ atoms ratio, such as $\mathrm{Ni}_{0.4} \mathrm{Ag}_{1} / \mathrm{SBA}-15$, a thicker $\mathrm{Ag}$ shell of $1.19 \mathrm{~nm}$ (refer to Figure $6 \mathrm{c}$ ) was obtained which led to poor PO activity $(2.3 \mathrm{nmol} / \mathrm{g} / \mathrm{s})$ and selectivity $(41.4 \%$, refer to Table 1$)$. In contrast, $\mathrm{Ni}_{1} \mathrm{Ag}_{0.4} / \mathrm{SBA}-15$, having a thinner Ag shell, showed relatively superior PO activity $(4.4 \mathrm{nmol} / \mathrm{g} / \mathrm{s})$ and selectivity $(70.7 \%)$. To further investigate the geometric and electronic features of local surface structure of Ag shell atoms with respect to catalytic performance, EXAFS and XPS were employed.

The local bonding structures of $\mathrm{Ag}$ shell atoms and $\mathrm{Ni}$ core atoms were analysed by EXAFS at $\mathrm{Ag}$ and $\mathrm{Ni}$ K-edges for the Ag/SBA-15, Ni/SBA-15, Ni $\mathrm{N}_{.2} \mathrm{Ag}_{1} / \mathrm{SBA}-15, \mathrm{Ni}_{0.4} \mathrm{Ag}_{1} / \mathrm{SBA}-15, \mathrm{Ni}_{1} \mathrm{Ag}_{0.4} / \mathrm{SBA}-15$ and $\mathrm{Ni}_{1} \mathrm{Ag}_{0.2} / \mathrm{SBA}$ 15. EXAFS fitting for $\mathrm{Ni}_{1} \mathrm{Ag}_{0.4} / \mathrm{SBA}-15$ in $\mathrm{k}$ and $\mathrm{R}$ spaces is selectively shown in Figure $\mathrm{S} 3$ and all data are summarised in Table 2 and Table S1. As seen from Table 2, each sample is fitted with 
a $\mathrm{R}$ factor of below $2.1 \%$ with the coordination number $(\mathrm{CN})$ found to be around 7.7 to 8.2 . Ag-Ni signal could not be fitted due to the large scattering parameter of $\mathrm{Ag}$. This $\mathrm{CN}$ value is typical for 3-5 $\mathrm{nm}$ nanoparticles with significant numbers of surface non-coordination sites (derivate from CN of 12 of bulk number) $[38,42]$. It is interesting to notice the difference in the average $\mathrm{Ag}-\mathrm{Ag}$ bond distance. For the $\mathrm{Ni}_{0.2} \mathrm{Ag}_{1} / \mathrm{SBA}-15$ and $\mathrm{Ni}_{0.4} \mathrm{Ag}_{1} / \mathrm{SBA}-15$ with thicker $\mathrm{Ag}$ shells, their average $\mathrm{Ag}-\mathrm{Ag}$ bond distance is comparable to that of the monometallic Ag/SBA-15 of $2.83 \pm 0.01 \AA$. With the increase in $\mathrm{Ni}$ to $\mathrm{Ag}$ atom ratio, as in the cases of $\mathrm{Ni}_{1} \mathrm{Ag}_{0.4} / \mathrm{SBA}-15$ and $\mathrm{Ni}_{1} \mathrm{Ag}_{0.2} / \mathrm{SBA}-15$, there is a clear expansion of $\mathrm{Ag}-\mathrm{Ag}$ bond of $2.85 \pm 0.01 \AA$ beyond the statistical errors although the value is very small. Regarding the differences in atomic size and energy potential of $\mathrm{Ni}$ and $\mathrm{Ag}$ atoms, there should have lattice mismatches and charge transfer due to difference in $d$-band energies of these two monometallic phases at the interface in Ag-Ni binary core-shell system $[36,43]$. Ideally, one should expect a compression in Ag lattice parameter exerted by the underlying $\mathrm{Ni}$ lattice, which has the same fcc crystal structure as $\mathrm{Ni}$ but with a larger lattice parameter (isomorphic effect) [44]. In contrast, an expansion in Ag-Ag interatomic distance is observed. This expansion is thought to be due to loosely packed surface $\mathrm{Ag}$ atoms from bulk phase since the percentage of surface atoms is overwhelmingly high in such thin atomic over-layers. As can be seen in Table S1, each Ni K-edge fitting has also an $\mathrm{R}$-factor below $2.6 \%$, which shows the average coordination number of $\mathrm{Ni}-\mathrm{Ni}$ in the samples is also around 8 indicative of nanoparticle size of the similar size created in SBA-15. However, for the $\mathrm{Ni} \mathrm{K}$-edge analysis, the additional $\mathrm{Ni}-\mathrm{Ag}$ coordination signals are evident, giving the total coordination numbers of 10-11. This high-coordination characteristic of Ni@Ag/SBA-15 samples clearly implies the $\mathrm{Ni}$ is in pseudo bulk-like position where the surface unsaturated $\mathrm{Ni}$ sites are in contact with $\mathrm{Ag}$ shell atoms in bimetallic core-shell structure, as agreeable to the data from advanced surface analyses $[36,45]$. This observation also matches with general higher CN of core atoms of core-shell structures [36,45-48]. It is interesting to note that the Ni-Ni bond of $2.48 \pm 0.01 \AA$ in $\mathrm{Ni}$ core nanoparticle this time, remains totally unchanged within the experimental error.

Table 2 Ag K-edge EXAFS data for Ag/SBA-15 and NiAg/SBA-15 catalysts. (Enot is difference in absorption energy between experiment and calculation)

\begin{tabular}{lccccc} 
Catalysts & $\begin{array}{c}C N \\
(A g-A g)\end{array}$ & $\begin{array}{c}D \text {-W factor } \\
(\text { Ag-Ag) }\end{array}$ & $\begin{array}{c}\text { Bond length, } \AA \\
(\text { Ag-Ag) }\end{array}$ & Enot & $\begin{array}{c}\text { R-factor } \\
\%\end{array}$ \\
\hline$A g / S B A-15$ & $8.0(3)$ & $0.013(1)$ & $2.83(1)$ & -0.3 & 1.9 \\
$\mathrm{Ni}_{0.2} \mathrm{Ag}_{1} / \mathrm{SBA}-15$ & $7.7(4)$ & $0.014(1)$ & $2.83(1)$ & -0.7 & 2.1 \\
$\mathrm{Ni}_{0.4} \mathrm{Ag}_{1} / \mathrm{SBA}-15$ & $7.8(3)$ & $0.014(1)$ & $2.83(1)$ & -1.4 & 2.0 \\
$\mathrm{Ni}_{1} \mathrm{Ag}_{0.4} / \mathrm{SBA}-15$ & $8.1(2)$ & $0.012(1)$ & $2.85(1)$ & 1.8 & 0.8 \\
$\mathrm{Ni}_{1} \mathrm{Ag}_{0.2} / \mathrm{SBA}-15$ & $8.2(2)$ & $0.013(1)$ & $2.85(1)$ & 1.9 & 0.7
\end{tabular}


XPS was employed to monitor the chemical state of $\mathrm{Ag}$ in these samples. Figure 8 shows $\mathrm{Ag} 3 \mathrm{~d}$ XPS spectra of the (a) $\mathrm{Ag} / \mathrm{SBA}-15$, (b) $\mathrm{Ni}_{0.2} \mathrm{Ag}_{1} / \mathrm{SBA}-15$, (c) $\mathrm{Ni}_{0.4} \mathrm{Ag}_{1} / \mathrm{SBA}-15$, (d) $\mathrm{Ni}_{1} \mathrm{Ag}_{0.4} / \mathrm{SBA}-15$, respectively. Two strong and distinct peaks at ca. 367.6 and $373.6 \mathrm{eV}$ are observed from the $\mathrm{Ag} 3 \mathrm{~d}$ XPS spectra, which can be attributed to $A g 3 d_{5 / 2}$ and $A g 3 d_{3 / 2}$, respectively [49]. Comparing to $\mathrm{Ag} / \mathrm{SBA}-15$, the $\mathrm{Ag} 3 \mathrm{~d}_{5 / 2}$ peak is progressively shifted to lower binding energies from 368.0 to the highest value of $367.6 \mathrm{eV}$ of $\mathrm{Ni}_{1} \mathrm{Ag}_{0.4} / \mathrm{SBA}-15$. This shift to lower $\mathrm{BE}$ may reflect the upshift of the surface $d$-band centre due to the geometric loosely packed interatomic Ag atoms in the shell [50]. On the other hand, considering the electronegativity (EN) values of $\mathrm{Ag}$ (1.93) and $\mathrm{Ni}$ (1.92), respectively, a slight tendency for an electron transfer may occur from the Ni phase to Ag phase leading to an increase in charge density of the Fermi level of Ag hence also accounting for the lower BE. Based on theoretical calculations [11] and our unreported experimental results, the selectivity of propylene oxide over $\mathrm{Ag}(100)$ is much higher than $\mathrm{Ag}(111)$. This is attributed to the isolated active oxygen adsorbed on this facet with longer $\mathrm{Ag}-\mathrm{Ag}$ interatomic distance for the effective epoxidation reaction. The neighboured oxyradical formed from dioxygen molecule on this facet does not catalyse the $\mathrm{y}-\mathrm{H}$ abstraction from the surface adsorbed oxygenated species in a favourable position to lead to the total combustion. Similarly, the synthesis of $\mathrm{Ni@Ag} \mathrm{core-shell} \mathrm{nanoparticle} \mathrm{and} \mathrm{tailoring} \mathrm{of} \mathrm{Ag-Ag}$ interatomic distance on $\mathrm{Ag}$ shell atoms may also provide a new way to create a longer $\mathrm{Ag}-\mathrm{Ag}$ distance to reduce the total combustion route. Such longer interatomic Ag distance resulted from lesser surface packing can raise the surface $d$ band centre to promote higher activity as according to the $d$ band theory [51-54]. This can account for the higher propylene oxide activity and selectivity observed for the first time on $\mathrm{Ni@Ag} \mathrm{core-shell} \mathrm{catalysts.} \mathrm{It} \mathrm{is} \mathrm{also} \mathrm{shown} \mathrm{that} \mathrm{the} \mathrm{ultra-thin} \mathrm{Ag} \mathrm{shell}$ atoms with $0.63 \mathrm{~nm}$ in the case of the $\mathrm{Ni}_{1} \mathrm{Ag}_{0.4} / \mathrm{SBA}-15$ can also activate the dioxygen directly without the assistance SMSI to give an optimal $70 \%$ selectivity to PO in direct propylene oxidation. The interesting question is that how the lattice expansion in Ag shell-atoms of the Ni@Ag core-shell nanoparticle can directly enhance the PO activity and selectivity. We do not anticipate a blunt 'epitaxyl like' interface between the two metal phases in multifaceted core-shell nanoparticle morphology but rather in the interface region which contains inter-exchanged atoms from both sides (as shown by the Ag shell contaminated with $\mathrm{Ni}$ atoms in APT in Figure 7), as similar to our previous characterization of CdTe-ZnO nano-interface by atom probe tomography [40]. Besides, the small but finite solubility (diffusion) between $\mathrm{Ni}$ and $\mathrm{Ag}$ phases and their difference in thermal expansion coefficient would make somehow irregular interface as contrast from that of singlecrystals studies [45]. Apart from the possible lattice expansion effects, hetero-metallic bonding interactions, termed as "ligand effect", between Ag atoms of lower Fermi energy and core Ni atoms of higher Fermi energy can result in charge transfer from $\mathrm{Ni}$ to $\mathrm{Ag}$ (also predicted by their difference 
in electronegativity), and thus decrease the activity of Ag atoms by $\mathrm{d}$-band shift and electron filling $[50,55,56]$. It is difficult to assess the relative lattice strain and ligand effects because they occur simultaneously [43]. It is thought that both these lattice strain and ligand effects play the role(s) to the activity of the $\mathrm{Ag}$ shell atoms. However, we believe lattice expansion overwhelms the ligand effect as one could expect to observe lower PO selectivity when Ag surface is less electrophilic. Electronically rich $\mathrm{Ag}$ surface might be detrimental for the adsorption of oxygen and/or lead adsorbed oxygen to be more basic with a tendency to attack allylic hydrogen of propylene.

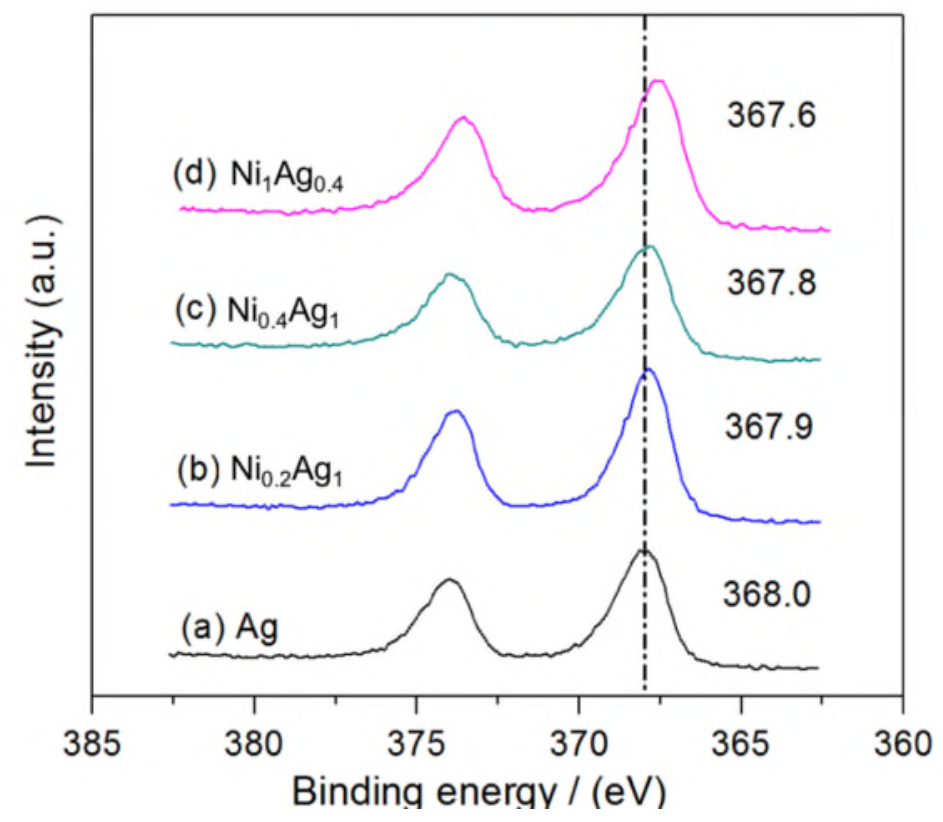

Figure 8 XPS spectra of Ag/SBA-15 and selected NiAg/SBA-15 catalysts.

\section{Conclusion}

The introduction of $\mathrm{Ni}$ nano-core to host $\mathrm{Ag}$ atoms offers a new way to create lattice expansion (geometric) and charge transfer (electronic) modification of Ag phase, which shows contrasting effect for catalytic performance on direct propylene epoxidation reaction. Careful control of shell thickness creates lattice expansion of Ag phase which leads to enhanced catalytic performance on direct propylene epoxidation reaction. These new core-shell catalysts present excellent stability over prolonged stability test, which can maintain the conversion and selectivity for at least $10 \mathrm{~h}$ in our small-scale laboratory testing. Even more studies are necessary to increase the propylene conversion to industrially desired conditions; this study paves the way to high selectivity over Ag nanoparticles even in small scale (small Ag particles were found to be detrimental for high PO selectivity) in the absence of strong metal-support interaction simply by tailoring the surface properties structurally and electronically. 


\section{Conflicts of interest}

There are no conflicts of interest to declare.

\section{Acknowledgements}

We thank King Abdulaziz City for Science and Technology (KACST) of Saudi Arabia and the EPSRC of UK (EP/K040375/1) for supporting this work. The authors wish to thank the access of XAS facilities at B18 from Diamond Light Source, UK.

\section{References}

[1] S.J. Khatib, S.T. Oyama, Direct Oxidation of Propylene to Propylene Oxide with Molecular Oxygen: A Review, Catal. Rev. 57 (2015) 306-344. doi:10.1080/01614940.2015.1041849.

[2] J. Huang, M. Haruta, Gas-phase propene epoxidation over coinage metal catalysts, Res Chem Intermed. 38 (2012) 1-24. doi:10.1007/s11164-011-0424-6.

[3] K. Singh, K. Merchant, Handbook of Industrial Chemistry And Biotechnology, in:Handbook of Industrial Chemistry and Biotechnology, in: Handb. Ind. Chem. Biotechnol., 2012: pp. 643698.

[4] M. Mohri, Y. Uchida, Y. Sawabe, Japan Patent H6-191835, Japan Pat. H6-191835. (1994).

[5] J.G. Serafin, A.C. Liu, S.R. Seyedmonir, Surface science and the silver-catalyzed epoxidation of ethylene: An industrial perspective, J. Mol. Catal. A Chem. 131 (1998) 157-168. doi:10.1016/S1381-1169(97)00263-X.

[6] Q. Hua, T. Cao, X.K. Gu, J. Lu, Z. Jiang, X. Pan, L. Luo, W.X. Li, W. Huang, Crystal-planecontrolled selectivity of Cu2O catalysts in propylene oxidation with molecular oxygen, Angew. Chemie - Int. Ed. 53 (2014) 4856-4861. doi:10.1002/anie.201402374.

[7] P. Christopher, S. Linic, Engineering selectivity in heterogeneous catalysis: Ag nanowires as selective ethylene epoxidation catalysts, J. Am. Chem. Soc. 130 (2008) 11264-11265. doi:10.1021/ja803818k.

[8] R.M. Lambert, F.J. Williams, R.L. Cropley, A. Palermo, Heterogeneous alkene epoxidation: past, present and future, J. Mol. Catal. A Chem. 228 (2005) 27-33. doi:10.1016/j.molcata.2004.09.077.

[9] X. Zheng, Q. Zhang, Y. Guo, W. Zhan, Y. Guo, Y. Wang, G. Lu, Epoxidation of propylene by molecular oxygen over supported Ag-Cu bimetallic catalysts with low Ag loading, J. Mol. Catal. A Chem. 357 (2012) 106-111. doi:10.1016/j.molcata.2012.01.027.

[10] D. Torres, N. Lopez, F. Illas, R.M. Lambert, Low-Basicity Oxygen Atoms: A Key in the Search for Propylene Epoxidation Catalysts, Angew. Chemie Int. Ed. 46 (2007) 2055-2058. doi:10.1002/anie.200603803. 
[11] A. Pulido, P. Concepción, M. Boronat, A. Corma, Aerobic epoxidation of propene over silver (111) and (100) facet catalysts, J. Catal. 292 (2012) 138-147. doi:10.1016/j.jcat.2012.05.006.

[12] Q. Zhang, G. Chai, Y. Guo, W. Zhan, Y. Guo, L. Wang, Y. Wang, G. Lu, Gas-phase epoxidation of propylene by molecular oxygen over $\mathrm{Ag}-\mathrm{CuCl} 2 / \mathrm{BaCO}$ catalyst with low $\mathrm{CuCl}$ 2doping: Catalytic performance, deactivation and regeneration, J. Mol. Catal. A Chem. 424 (2016) 65-76. doi:10.1016/j.molcata.2016.08.019.

[13] Y. Lei, F. Mehmood, S. Lee, J. Greeley, B. Lee, S. Seifert, R.E. Winans, J.W. Elam, R.J. Meyer, P.C. Redfern, D. Teschner, R. Schlögl, M.J. Pellin, L. a Curtiss, S. Vajda, Increased silver activity for direct propylene epoxidation via subnanometer size effects., Science. 328 (2010) 224-8. doi:10.1126/science.1185200.

[14] L.M. Molina, S. Lee, K. Sell, G. Barcaro, A. Fortunelli, B. Lee, S. Seifert, R.E. Winans, J.W. Elam, M.J. Pellin, I. Barke, V. Von Oeynhausen, Y. Lei, R.J. Meyer, J.A. Alonso, A. Fraile Rodríguez, A. Kleibert, S. Giorgio, C.R. Henry, K.H. Meiwes-Broer, S. Vajda, Size-dependent selectivity and activity of silver nanoclusters in the partial oxidation of propylene to propylene oxide and acrolein: A joint experimental and theoretical study, Catal. Today. 160 (2011) 116-130. doi:10.1016/j.cattod.2010.08.022.

[15] D. Sullivan, P. Hooks, M. Mier, J.W. Van Hal, X. Zhang, Effect of support and preparation on silver-based direct propylene epoxidation catalyst, Top. Catal. 38 (2006) 303-308. doi:10.1007/s11244-006-0029-2.

[16] R.P. Wang, X.W. Guo, X.S. Wang, J.Q. Hao, Propylene epoxidation over silver supported on titanium silicalite zeolite, Catal. Letters. 90 (2003) 57-63.

[17] Q. Zhang, Y. Guo, W. Zhan, Y. Guo, L. Wang, Y. Wang, G. Lu, Gas-phase epoxidation of propylene by molecular oxygen over $\mathrm{Ag} / \mathrm{BaCO}$ catalysts: Effect of preparation conditions, Catal. Today. 276 (2016) 2-10. doi:10.1016/j.cattod.2016.01.015.

[18] M.M.-J. Li, L. Ye, J. Zheng, H. Fang, A. Kroner, Y. Yuan, S.C.E. Tsang, Surfactant-free nickelsilver core@shell nanoparticles in mesoporous SBA-15 for chemoselective hydrogenation of dimethyl oxalate, Chem. Commun. 52 (2016) 2569-2572. doi:10.1039/C5CC09827K.

[19] D. Zhao, Q. Huo, J. Feng, B.F. Chmelka, G.D. Stucky, Nonionic Triblock and Star Diblock Copolymer and Oligomeric Surfactant Syntheses of Highly Ordered, Hydrothermally Stable, Mesoporous Silica Structures, J. Am. Chem. Soc. 120 (1998) 6024-6036. doi:Doi 10.1021/Ja974025i.

[20] A. Takahashi, N. Hamakawa, I. Nakamura, T. Fujitani, Effects of added 3d transition-metals on Ag-based catalysts for direct epoxidation of propylene by oxygen, Appl. Catal. A Gen. 294 (2005) 34-39. doi:10.1016/j.apcata.2005.06.026. 
[21] T.A. Nijhuis, M. Makkee, J. a. Moulijn, B.M. Weckhuysen, The Production of Propene Oxide: Catalytic Processes and Recent Developments, Ind. Eng. Chem. Res. 45 (2006) 34473459. doi:10.1021/ie0513090.

[22] J. Hagen, Industrial Catalysis: A Practical Approach, Wiley-VCH Verlag GmbH, 2006.

[23] L. Lloyd, Handbook of Industrial Catalysts: Fundamental and Applied Catalysis, Springer Science \& Business Media, 2011.

[24] G. Centi, F. Cavani, F. Trifiro, selective oxidation by heterogeneous catalysis, Kluwer Academic/Plenum Publishers, 1992.

[25] T. Okazawa, T. Nishizawa, T. Nishimura, Y. Kido, Oxidation kinetics for $\mathrm{Ni}$ (111) and the structure of the oxide layers, Phys. Rev. B. 75 (2007) 33413. doi:10.1103/PhysRevB.75.033413.

[26] L. De Los Santos Valladares, A. Ionescu, S. Holmes, C.H.W. Barnes, A. Bustamante Domínguez, O. Avalos Quispe, J.C. González, S. Milana, M. Barbone, A.C. Ferrari, H. Ramos, Y. Majima, Characterization of $\mathrm{Ni}$ thin films following thermal oxidation in air, J. Vac. Sci. Technol. B, Nanotechnol. Microelectron. Mater. Process. Meas. Phenom. 32 (2014) 051808. doi:10.1116/1.4895846.

[27] S. Ghosh, S.S. Acharyya, R. Tiwari, B. Sarkar, R.K. Singha, C. Pendem, T. Sasaki, R. Bal, Selective Oxidation of Propylene to Propylene Oxide over Silver Supported Tungsten Oxide Nanostructure with Molecular Oxygen, ACS Catal. 4 (2014) 2169-2174. doi:10.1021/cs5004454.

[28] F.W. Zemichael, A. Palermo, M.S. Tikhov, R.M. Lambert, Propene Epoxidation over KPromoted Ag / CaCO3 Catalysts: The Effect of Metal Particle Size, Catal. Letters. 80 (2002) 93-98. doi:10.1023/A.

[29] Y. Wang, M. Noguchi, Y. Takahashi, Y. Ohtsuka, Synthesis of SBA-15 with different pore sizes and the utilization as supports of high loading of cobalt catalysts, Catal. Today. 68 (2001) 3-9. doi:10.1016/S0920-5861(01)00317-0.

[30] F.Q. Zhang, Y. Yan, H.F. Yang, Y. Meng, C.Z. Yu, B. Tu, D.Y. Zhao, Understanding effect of wall structure on the hydrothermal stability of mesostructured silica SBA-15, J. Phys. Chem. B. 109 (2005) 8723-8732. doi:10.1021/jp044632+.

[31] W. Yue, W. Zhou, Crystalline mesoporous metal oxide, Prog. Nat. Sci. 18 (2008) 1329-1338. doi:10.1016/j.pnsc.2008.05.010.

[32] M. Kumar, S. Deka, Multiply twinned AgNi alloy nanoparticles as highly active catalyst for multiple reduction and degradation reactions, ACS Appl. Mater. Interfaces. 6 (2014) 1607116081. doi:10.1021/am503913y.

[33] J.K. Bording, B.Q. Li, Y.F. Shi, J.M. Zuo, Size- and shape-dependent energetics of nanocrystal 
interfaces: Experiment and simulation, Phys. Rev. Lett. 90 (2003) 2261041-2261044. doi:10.1103/PhysRevLett.90.226104.

[34] S. Adhikari, G. Madras, Role of $\mathrm{Ni}$ in hetero-architectured $\mathrm{NiO} / \mathrm{Ni}$ composites for enhanced catalytic performance, Phys. Chem. Chem. Phys. 19 (2017) 13895-13908. doi:10.1039/C7CP01332A.

[35] F. Calvo, E. Cottancin, M. Broyer, Segregation, core alloying, and shape transitions in bimetallic nanoclusters: Monte Carlo simulations, Phys. Rev. B - Condens. Matter Mater. Phys. 77 (2008) 1-4. doi:10.1103/PhysRevB.77.121406.

[36] A. Rapallo, G. Rossi, R. Ferrando, A. Fortunelli, B.C. Curley, L.D. Lloyd, G.M. Tarbuck, R.L. Johnston, Global optimization of bimetallic cluster structures. I. Size-mismatched $\mathrm{Ag}-\mathrm{Cu}, \mathrm{Ag}-$ $\mathrm{Ni}$, and Au-Cu systems, J. Chem. Phys. 122 (2005) 194308. doi:10.1063/1.1898223.

[37] F. Baletto, C. Mottet, A. Rapallo, G. Rossi, R. Ferrando, Growth and energetic stability of AgNi core-shell clusters, Surf. Sci. 566-568 (2004) 192-196. doi:10.1016/j.susc.2004.05.044.

[38] K. Tedsree, T. Li, S. Jones, C.W.A. Chan, K.M.K. Yu, P.A.J. Bagot, E.A. Marquis, G.D.W. Smith, S.C.E. Tsang, Hydrogen production from formic acid decomposition at room temperature using a Ag-Pd core-shell nanocatalyst, Nat. Nanotechnol. 6 (2011) 302-307. doi:10.1038/nnano.2011.42.

[39] T. Li, P.A.J. Bagot, E. Christian, B.R.C. Theobald, J.D.B. Sharman, D. Ozkaya, M.P. Moody, S.C.E. Tsang, G.D.W. Smith, Atomic imaging of carbon-supported Pt, Pt/Co, and Ir@Pt nanocatalysts by atom-probe tomography, ACS Catal. 4 (2014) 695-702. doi:10.1021/cs401117e.

[40] C. Eley, T. Li, F. Liao, S.M. Fairclough, J.M. Smith, G. Smith, S.C.E. Tsang, Nanojunctionmediated photocatalytic enhancement in heterostructured $\mathrm{CdS} / \mathrm{ZnO}, \mathrm{CdSe} / \mathrm{ZnO}$, and CdTe/ZnO nanocrystals, Angew. Chemie - Int. Ed. 53 (2014) 7838-7842. doi:10.1002/anie.201404481.

[41] M.K. Miller, R.G. Forbes, Atom probe tomography, Mater. Charact. 60 (2009) 461-469. doi:10.1016/j.matchar.2009.02.007.

[42] G. Agostini, R. Pellegrini, G. Leofanti, L. Bertinetti, S. Bertarione, E. Groppo, A. Zecchina, C. Lamberti, Determination of the particle size, available surface area, and nature of exposed sites for silica-alumina-supported Pd nanoparticles: A multitechnical approach, J. Phys. Chem. C. 113 (2009) 10485-10492. doi:10.1021/jp9023712.

[43] J.R. Kitchin, J.K. Nrskov, M.A. Barteau, J.G. Chen, Role of strain and ligand effects in the modification of the electronic and chemical Properties of bimetallic surfaces, Phys. Rev. Lett. 93 (2004) 4-7. doi:10.1103/PhysRevLett.93.156801.

[44] E. Roduner, Size matters: why nanomaterials are different, Chem. Soc. Rev. 35 (2006) 583. 
doi:10.1039/b502142c.

[45] M. Harb, F. Rabilloud, D. Simon, Structural, electronic, magnetic and optical properties of icosahedral silver-nickel nanoclusters, Phys Chem Chem Phys. 12 (2010) 4246-4254. doi:10.1039/b912971e.

[46] M. Harada, K. Asakura, N. Toshima, Catalytic activity and structural analysis of polymerprotected gold/palladium bimetallic clusters prepared by the successive reduction of hydrogen tetrachloroaurate(III) and palladium dichloride, J. Phys. Chem. 97 (1993) 5103-5114. doi:10.1021/j100121a042.

[47] T. Balcha, J.R. Strobl, C. Fowler, P. Dash, R.W.J. Scott, Selective aerobic oxidation of crotyl alcohol using aupd core-shell nanoparticles, ACS Catal. 1 (2011) 425-436. doi:10.1021/cs200040a.

[48] F. Liu, D. Wechsler, P. Zhang, Alloy-structure-dependent electronic behavior and surface properties of Au-Pd nanoparticles, Chem. Phys. Lett. 461 (2008) 254-259. doi:10.1016/j.cplett.2008.07.029.

[49] C.D. Wagner, Handbook of X-ray Photoelectron Spectroscopy, PerkinElmer, 1979.

[50] J.R. Kitchin, J.K. Nørskov, M.A. Barteau, J.G. Chen, Modification of the surface electronic and chemical properties of Pt(111) by subsurface 3d transition metals, J. Chem. Phys. 120 (2004) 10240-10246. doi:10.1063/1.1737365.

[51] S. Bhattacharjee, U. V. Waghmare, S.C. Lee, An improved d-band model of the catalytic activity of magnetic transition metal surfaces, Sci. Rep. 6 (2016) 1-10. doi:10.1038/srep35916.

[52] H. Abe, H. Yoshikawa, N. Umezawa, Y. Xu, G. Saravanan, G. V. Ramesh, T. Tanabe, R. Kodiyath, S. Ueda, N. Sekido, Y. Yamabe-Mitarai, M. Shimoda, T. Ohno, F. Matsumoto, T. Komatsu, Correlation between the surface electronic structure and CO-oxidation activity of Pt alloys, Phys. Chem. Chem. Phys. 17 (2015) 4879-4887. doi:10.1039/C4CP03406F.

[53] E. Toyoda, R. Jinnouchi, T. Hatanaka, Y. Morimoto, K. Mitsuhara, A. Visikovskiy, Y. Kido, The dband structure of Pt nanoclusters correlated with the catalytic activity for an oxygen reduction reaction, J. Phys. Chem. C. 115 (2011) 21236-21240. doi:10.1021/jp206360e.

[54] M. Mavrikakis, B. Hammer, J.K. Nørskov, Effect of strain on the reactivity of metal surfaces, Phys. Rev. Lett. 81 (1998) 2819-2822. doi:10.1103/PhysRevLett.81.2819.

[55] J.A. Rodriguez, D.W. Goodman, The Nature of the Metal-Metal Bond in Bimetallic Surfaces, Science (80-. ). 257 (1992) 897-903. doi:10.1126/science.257.5072.897.

[56] A. Schlapka, M. Lischka, A. Groß, U. Käsberger, P. Jakob, Surface Strain versus Substrate Interaction in Heteroepitaxial Metal Layers: Pt on Ru(0001), Phys. Rev. Lett. 91 (2003) 016101. doi:10.1103/PhysRevLett.91.016101. 